\title{
Trusting consumers: Involving communities in municipal water service decision making in Durban, South Africa
}

\author{
Zoë Wilson ${ }^{1 *}$, Mandla Malakoana ${ }^{2}$ and Teddy Gounden ${ }^{3}$ \\ ${ }^{1}$ Pollution Research Group/School of Development Studies, University of KwaZulu-Natal, Durban 4001, South Africa; \\ Department of Urban Studies and Planning, Massachusetts Institute of Technology, Cambridge, USA, 02139-4307 \\ ${ }^{2}$ eThekwini Water and Sanitation, Durban 4001, South Africa \\ ${ }^{3}$ eThekwini Water and Sanitation, Durban 4001, South Africa
}

\begin{abstract}
The Constitution of 1996 sets out the government's responsibility to provide the public with the opportunity to be involved in government decisions that affect their lives (R Kasrils, Former Minister of Water Affairs and Forestry, 2001)

Participation is a guiding principle of South Africa's post-apartheid water sector reforms. Yet studies indicate that substantive and effective participation has been difficult to achieve. In an effort to develop sustainable and creative dialogue with consumers, the University of KwaZulu-Natal in partnership with eThekwini Water and Sanitation (EWS) piloted the establishment of community-based focus groups in 3 different types of communities. The goals of the project were to build trust, generate social capital and widen the store of available methods for enhancing dialogue between service providers and consumers. This paper details the methods used. This pilot formed part of a larger strategy to develop and refine a methodology to be used in a municipality-wide research and engagement strategy involving a diverse selection of wards. At the time of publication, research in 6 wards and one similar study with people with disabilities were complete.
\end{abstract}

Keywords: participation, trust, water service improvement

\section{Introduction: Theoretical framework}

The South African water sector was institutionally reformed by the National Water Act of 1998 and the Water Services Act of 1997 (DWAF, undated). These Acts recognise that 'past laws relating to water resources were discriminatory and not appropriate to South African conditions.' Further, 'Without public participation, the goals of water resource management cannot be achieved.' (DWAF, 2005). Since that time, a large number of workshops and events have taken place aimed at advertising the change, soliciting public dialogue and input, and networking the new water sector infrastructure and competencies together. This reflects an understanding that scientifically sound and technologically viable projects must also be socially feasible (Harrison et al., 2004). Further, consumers have important insights into how service providers can meet their needs, and these insights are best integrated early and throughout planning and implementation (Sigodi, Marah, Martin, 2007).

Yet, over the past 10 years, participation in the water and sanitation sector in eThekwini municipality (formerly City of Durban) has been weak, dominated by a conflict-based complaint ethic on the part of social movements (Desai, 2002), and a general lack of available models of participation and corresponding forums for constructive engagement between the Municipality and the general citizenry (Macleod, 2007). It is recognised, however, that better information flow between consumers and eThekwini Water and Sanitation (EWS) is required for the Department to accelerate learning to sustainably meet the challenge of service backlogs. In part this means developing mecha-

\footnotetext{
* To whom all correspondence should be addressed.

III +2731 260-2917; +27 74 179 3175; fax: +27 312602359 ;

e-mail: wilsonz@ukzn.ac.z

Received 10 July 2007; accepted in revised form 30 December 2007.
}

nisms for bringing local knowledge to bear on finding innovative new solutions to complex and intractable problems, such as vandalism of infrastructure and consequently high non-revenue water rates (over $30 \%$ ). While a number of participatory initiatives are underway in the South African water sector, the absence of a clear workable model for creative dialogue suggested there was room for further practical research contributions.

Durban's participatory deficit is not unique. Generally, across many sectors, consultative processes are criticised for being pro forma, ad hoc and politicised (Wilson, 2006). In terms of South Africa's water sector, specifically, there are a number of studies pointing to widespread deficits, ranging from persistent knowledge and capacity gaps to local politics and gender inequities (Burt et al., 2006; Hagg and Emmet, 2003; Holden and Grossman, 2005; McClennan, 2007; Muller, 2007; Nicoli and Mtisi, 2003; Wilson and Perret, 2008). One reason for these is that mainstream efforts at participation have been based on the principles of conflict mitigation. They invite those stakeholders to the table who are most vocal and/or politically active as a means to achieve buy-in from groups most likely to create conflict. Here, conflict mitigation takes precedence over other objectives, such as bringing new ideas to the fore or scanning information landscapes for innovative solutions. In the conflict mitigation approach, the views of organised groups - especially those who use conflict to advance complaints typically take precedence over those of regular consumers, while de-emphasising the needs of less vocal or less wellorganised disadvantaged groups and categories of persons. Yet, where conflict mitigation is the primary goal, there is little evidence that appeasement leads to sustained creative dialogue or fresh solutions in the water sector.

In a recent state-of-the-art report by Sigodi, Marah, Martin (2007) for the Water Research Commission 'community 
consultation' was broadly defined to include 'all types of communication aimed at the general public, ranging from information dissemination to community participation.' Further, the report notes that 'Outcomes sought....are typically awareness, attitude change, or behavioural change.' (Sigodi, Marah, Martin, 2007). This report also served to highlight that contemporary participatory processes tend to be based on enlisting local organisations and politically active citizens in order to achieve conflict mitigation. Recent efforts in Cape Town, for example, to 'raise the community voice' selected only areas with strong community structures noting that: 'The project will work with existing community structures in each of selected sites with the aim of integrating a consumer oversight role' (Sigodi, Marah, Martin, 2007). Further, the project adopted a 'usual suspects' approach to building multi-stakeholder involvement: 'Establish a coalition of NGOs and CBOs that are interested in service delivery oversight to play a supportive role for this pilot. Suggested bodies include Environmental Monitoring Group, Anti-Eviction Campaign, Khayelitsha Development Forum, Tsoha, SAMWU, Rate Payer's Associations, Contemporary Research Foundation, IDASA and so forth' (Sigodi, Marah, Martin, 2007).

Reflected is the standard stakeholder approach to participation, which prescribes, as Junker et al. (2007) note: 'only those stakeholders should become involved who have legitimate and urgent claims, as well as the necessary political power to cause conflicts and to hinder or block a given project.' Also reflected is the presumption that the most vocal groups accurately represent community interests and the breadth of valuable contextualised knowledge the consultative process can ideally surface. In practice, however, NGOs and CBOs are rarely straightforwardly representative (Alcoff, 1991; Wilson, 2006). There is also clear evidence of overall poor performance in terms of outcomes sought by this method. For example, despite the Department of Water Affairs and Forestry's wide communication of reforms, Sigodi, Marah, Martin report that by 2007 , ' $40.8 \%$ of the adult population have heard of FBW [Free Basic Water]; $59.2 \%$ have not' and ' $25.7 \%$ of the adult population who have heard of FBW, believe that it means that water is for free - as much as you want.' (Sigodi, Marah, Martin, 2007).

Mainstream participatory approaches based on conflict avoidance are appropriate where conflict mitigation is the sole or main goal. This is rarely the case in the water sector where health, environmental and infrastructure concerns tend to pre-dominate. Further, adopting a conflict mitigation approach sends the message that the threat of conflict secures an invite to the policy table, thereby providing clear incentives for a conflict-based complaint ethic. Country-wide a conflictbased complaint ethic remains strong. In recent years, protests over basic services have been numerous and widespread. In late 2005, the Minister of Safety and Security released figures showing 5085 legal and 881 illegal gatherings and demonstrations for the 2004/05 financial year. Many of these related to basic services. Booysen's (2007) research, however, indicates that protest is often a preferred - not induced - mode of complaint, and therefore not evidence of more intractable participatory deficits, as often supposed (Bond, 2006). Nevertheless, inadequate participatory processes affect the legitimacy of initiatives and reduce the likelihood that people and groups will perceive interventions as reasonable (Ashton and Haasbroek, 2001; Ballard et al., 2006; Hagg and Emmett, 2003; Wilson and Hazell, 2006). In contrast to conflict-based models, a growing body of international water sector studies highlight the importance of building trust to achieve creative and productive dialogue with equitably beneficial outcomes (Mostert 2003; Pahl-Wostl, 2002)

\section{Introduction to study}

eThekwini Municipality (formerly City of Durban) spans an area of $2297 \mathrm{~km}^{2}$. It is home to a population of approximately 3.5 million people, of many faiths, cultural, religious, and ethnic affiliations. The legacy of apartheid contributes to groups remaining spatially segregated into relatively discrete racial, cultural and economic groupings, and service and satisfaction levels can vary significantly from ward to ward (See Table 1 - for example from pilot survey results). As a complement to traditional public engagement strategies, a 3 -area pilot study centred around trust-building was initiated. For the pilot study, 3 communities varying by general racial and socio-economic level were selected on the basis of EWS databases. A range of different types of communities were selected in order to test how well the initiative achieved objectives across different settings, as well as how perceptions of key issues varied from area to area. All 3 communities were fully reticulated. Two communities were isiZulu speaking, varying by socio-economic level, with KwaMashu Ward 40 representing a relatively economically deprived area and uMlazi $\mathrm{aa} / \mathrm{bb}$ representing a comparatively more well-off isiZulu-speaking area. Newlands East, Ward 11 was used to represent a relatively economically deprived Indian area. Post-pilot phase study areas, which are not discussed further here, have included both historically privileged and peri-urban areas.

\begin{tabular}{|l|c|c|c|c|}
\hline \multicolumn{5}{|c|}{ TABLE 1 } \\
\hline $\begin{array}{l}\text { Differing experiences } \\
\text { I am generally satis- } \\
\text { fied with water and } \\
\text { sanitation services } \\
\text { in this area }\end{array}$ & Agree & $\begin{array}{c}\text { Dis- } \\
\text { agree }\end{array}$ & $\begin{array}{c}\text { I don't } \\
\text { know }\end{array}$ & $\begin{array}{c}\text { No } \\
\text { answer }\end{array}$ \\
\hline uMlazi & $88 \%$ & $6 \%$ & $6 \%$ & \\
\hline KwaMashu & $42 \%$ & $42 \%$ & $4 \%$ & $14 \%$ \\
\hline Newlands East & $69 \%$ & $21 \%$ & $8 \%$ & $2 \%$ \\
\hline
\end{tabular}

\section{Participant selection}

Studies noted above suggest that key challenges to substantive participation in the water sector have included the adoption of strategies that have played into or exacerbated partisan political conflicts:

- Privileged 'the usual suspects' (i.e. more vocal political and politicised groups) over regular citizens

- Defined communities in ways that re-entrenched local inequities (particularly related to gender)

- Bolstered a conflict-based complaint ethic and failed to build trust, or social capital, or establish sustainable parameters for on-going dialogue among diverse types of actors.

In this light, the project understood the key conceptual problems as follows:

- How to define community?

- Who should represent community-based knowledge?

- How can diverse views be valued?

- How can sustained interest in creative dialogue be generated?

With these challenges in mind, the project adopted four conceptual building blocks:

- Community as social network: There are a number of different ways 'community' can be defined. We defined it as a network of social relationships characterised by an internal density and mediated by key institutions (Breiger, 2004; 
Moody and White, 2003); that is, individuals of the same community are embedded in a high number of shared relationships and links (i.e. children go to the same school; people shop at the same stores, etc.). These shared institutional links are more numerous inside 'the community'; indeed, it is their density that constitutes the community.

- Community-based knowledge: In line with our definition of community, we chose to engage people from anchor institutions, such as the schools, clinics, small businesses and churches. The emphasis was placed on people who live and work in the community, come into contact with a large number of people every day and who have a professional stake in community well being. These actors are not understood as speaking for or representing the community - nor do they make these claims - but rather they represent knowledge from important interchange points in the network (see also discussion below).

- Diversity over representivity: Communities are usefully defined in network terms. Networks are typically made up of smaller and overlapping networks. Thus communities are, in fact, clusters of overlapping networks (religious clusters, business-customer clusters, educational clusters and so on). We sought to cut across the various networks and cliques that co-exist within the same civic/geographical boundary. To this end, we chose many different and unrelated institutional entry points at once and monitored the network links between those being interviewed, so as not to over-represent one cluster of related people or interests.

- Trust is critical to effective engagement: Studies indicate that people's acceptance of municipal initiatives is based in large part on trust. Trust can be either general or specific. That is, trust can be high in the abstract, but nevertheless absent in relation to a specific initiative. We assumed that levels of trust in relation to this specific initiative would be low and designed a research strategy to serve as an 'ice breaker'. This included a visible and transparent research strategy, a survey tool, capacity-building measures, feedback opportunities and dialogue forums all geared towards building trust and sustainability.

In summary, then, the participant selection established that research processes would focus in building trust over conflict mitigation. Further, bearing in mind that the politics of representation is, itself, a major source of conflict, the project sought to engage through a purposive yet diverse sample comprising people who were likely to be broadly considered both impartial and best placed to comment on the link between the well being of community members and water and sanitation services.

The sample comprised 2 to 3 people each linked to key community institutions, such as crèches, schools, religious and social welfare organisations, clinics, small business owners, etc. Selected were people who live and work in the area, and have a professional responsibility for the health and well-being of large numbers of community members. The emphasis placed on working and living in the area biased the sample towards people who were both familiar with and residing at a similar socioeconomic level as the community more generally. In particular, low paid crèche workers and informal business owners of hair salons often expressed acute poverty issues associated with periodic unemployment and large households, especially where the participant was the only working member of household. As Table 2 illustrates, poverty issues came out strongly in the study surveys.

\begin{tabular}{|l|c|c|c|c|}
\hline \multicolumn{4}{|c|}{ PABLE 2 } \\
\hline $\begin{array}{l}\text { Perceptions of affordability } \\
\text { who cannot afford to } \\
\text { pay their water bills or } \\
\text { who have been discon- } \\
\text { nected or restricted in } \\
\text { the last year }\end{array}$ & $\begin{array}{c}\text { Dis- } \\
\text { agree }\end{array}$ & $\begin{array}{c}\text { I don't } \\
\text { know }\end{array}$ & $\begin{array}{c}\text { No } \\
\text { answer }\end{array}$ & \\
\hline uMlazi & $77 \%$ & $15 \%$ & $8 \%$ & \\
\hline KwaMashu & $79 \%$ & $9 \%$ & $11 \%$ & $2 \%$ \\
\hline Newlands East & $81 \%$ & $10 \%$ & $5 \%$ & $5 \%$ \\
\hline
\end{tabular}

Some schools in two of the pilot areas exhibited significant disrepair, at least one with no functioning water and sanitation services. One school teacher complained of not being able to pay her municipal rates and struggling with water disconnections. The views of clinic and home-based care workers were also useful for surfacing information about people in crisis who are typically unwilling to participate for reasons of stigma and/or because they are squatting illegally in abandoned homes or on council land, or otherwise physically unable (A post-pilot phase case study targeted people with physical disabilities in particular). People were also invited to identify one other person they felt should participate and no restrictions applied. Volunteers, part-time and temporary workers and the unemployed were not excluded from the sample. Further, the research was widely advertised in each area, and anyone who expressed an interest in participation was welcome under the caveat that they represented only their own point of view, not that of any political or institutional affiliation, and not more than 3 people associated with any given institution would be interviewed in order to ensure an overall diversity of perspectives.

In general there was significant interest among people interviewed in participating in on-going dialogue with EWS (see Table 3).

\begin{tabular}{|l|c|c|c|c|}
\hline \multicolumn{4}{|c|}{ LABLE 3 } \\
\hline $\begin{array}{l}\text { L would be interested in of initial interest } \\
\text { sitting on a Consulta- } \\
\text { tive Standing Group } \\
\text { that meets with EWS } \\
\text { three to four times a } \\
\text { year }\end{array}$ & $\begin{array}{c}\text { Dis- } \\
\text { agree }\end{array}$ & $\begin{array}{c}\text { I don't } \\
\text { know }\end{array}$ & $\begin{array}{c}\text { No } \\
\text { answer }\end{array}$ & \\
\hline uMlazi & $73 \%$ & $21 \%$ & $4 \%$ & $2 \%$ \\
\hline KwaMashu & $57 \%$ & $20 \%$ & $9 \%$ & $14 \%$ \\
\hline Newlands East & $58 \%$ & $36 \%$ & $3 \%$ & $3 \%$ \\
\hline
\end{tabular}

\section{Research processes}

Processes were developed to invest in social capital for sustained dialogue. This would be accomplished through:

- A community engagement strategy that was open, transparent and built trust

- Engagement with a purposeful sample whose impartiality and authoritativeness in terms of commenting on the link between community health and well-being and water and sanitation services would not be the subject of dispute

- A questionnaire whose results could serve as a legitimate departure point for discussion (i.e. make either consensus or divergence of 'community' opinion apparent on all or most issues of interest to the group)

- A report-back meeting where results are discussed between survey participants and EWS senior management 
- Focus groups formed sustained interest in dialogue generated, as evidenced by attendance at subsequent focusgroup meetings.

These processes are discussed further below.

The community engagement strategy: The engagement strategy was labour intensive and designed to be highly visible. It was initiated by identifying the nature and location of key institutions using GIS maps of the area. This was followed by a reconnaissance in the area, where researchers visited these and other unmapped institutions with letters of introduction and project information. There a request was made for permission to follow up with two to three affiliated individuals with an appointment to conduct the survey (Departmental permissions obtained in advance). Each contact was left with a clear itinerary for the research, information about when they would be contacted by phone in order to arrange a specific interview time and on which days the research team would be in the area conducting interviews. IsiZulu translation was readily available for all participants.

There was also a capacity building component. Local secondary schools were visited and a request made for the principal or vice-principal to help identify one or two recent graduates - ideally one from each secondary school - with an interest in research who would benefit from being employed as a research assistant and exposure to university-level research. The local research assistants were paired with University of KwaZuluNatal counterparts. Other services, such as catering for the meetings are also sourced locally. The majority of research is conducted by UKZN Master's students, as part of their degree training. In the words of one of the UKZN researchers:

I feel I gained a great deal from participating in this research project. I have improved my research skills in a number of areas. I travelled to different communities in eThekwini and obtained a detailed understanding of people's issues and concerns around access to water and community dynamics in eThekwini. I helped design, conduct and analyse questionnaires, arrange interviews, community report-backs, and develop a methodology for rapid, effective, non-political entry into and engagement with communities. I helped manage a research project, mentor local Research Assistants, have seen how dialogue can lead to constructive engagement between stakeholders and how relevant research can help policy makers understand their context and thus make informed decisions. I hope the research will continue in different communities, that more consultative standing groups will be formed and that ultimately these will provide a forum for community voice in water and sanitation decision making.

By being visible, providing community members with information to help benchmark the project's commitment and competence and by showing a commitment to building local capacity, the project was able to establish a trusted presence in the community. This engagement strategy was refined over the course of the 3-area pilot.

The sampling strategy: One of the most important unknowns for the pilot was whether a wide range of non-typical stakeholders would see our sampling approach as legitimate. Thus, every introduction and interview began by explaining that we planned to interview, primarily, people who live and work in the area, and who have a professional responsibility for the health and well-being of group of people, such as crèche workers, teachers and clinic nurses. By-and-large, most people considered this sample legitimate. This is true equally for participants working at these institutions, as well as for other types of participants (see section 2 for further discussion). People directly affiliated with the political structures were most likely to question this sampling approach, but this was rare. In a vast majority of cases people were untroubled by the extra-political nature of the engagement strategy and many expressed satisfaction with the ability to express their situated knowledge unmediated by political representatives or advocacy groups. At the time of publication, seven related studies were complete with no significant issues arising from the sampling strategy. It should be noted that this research programme is a complement to, not a replacement for, other more traditional public engagement /conflict mitigation strategies.

The survey questionnaire: The pilot study was initiated with a 104 question survey tool. The basis for the questionnaire was a related Department for International Development funded research project (Wilson, 2007), which conducted approximately 200 in-depth qualitative interviews and approximately 20 focus groups in several highly different settings around South Africa to surface a wide range of concerns related to water and sanitation services. This was supplemented by a comprehensive literature review. The issues covered by the questionnaire also resonated with the recent Water Research Commission Water Services Barometer study (Sigodi, Marah, Martin, 2007), but put a comparatively greater emphasis on the relationship between the water service provider and customer (see Table 4), and on pragmatic concerns operative in the day-to-day (i.e. location of leaky infrastructure). The barometer, moreover, measured general knowledge and awareness rather than relationships and grounded satisfaction levels.

\begin{tabular}{|l|c|c|c|}
\hline \multicolumn{4}{|c|}{ TABLE 4 } \\
Relationship between EWS and community \\
\hline $\begin{array}{l}\text { There have been conflicts } \\
\text { between EWS staff and people } \\
\text { living in this area }\end{array}$ & Agree & $\begin{array}{c}\text { Dis- } \\
\text { agree }\end{array}$ & $\begin{array}{c}\text { I don't } \\
\text { know }\end{array}$ \\
\hline uMlazi & $35 \%$ & $40 \%$ & $25 \%$ \\
\hline KwaMashu & $50 \%$ & $31 \%$ & $19 \%$ \\
\hline Newlands East & $21 \%$ & $55 \%$ & $24 \%$ \\
\hline
\end{tabular}

In general, respondents rated the early questionnaire as both comprehensive and onerous. After each field research episode, the research team reviewed comments made by participants about the questionnaire, as well as the clarity of questions and significance of responses. Ultimately the tool was refined down to 44 questions. Respondents remained satisfied with the breadth and depth of the 44 question tool. In the post pilot phase, the questionnaire was further refined to 28 questions, with no expression of dissatisfaction with breadth and scope reported by respondents.

That the questionnaire was perceived by participants to have been vetted by participants and to be asking the relevant and important questions, and was not perceived to bias or de-emphasise was critical to building trust. The tabulated results were ultimately made available to all the respondents and this shared body of information about the relative distribution of opinions about key issues was gathered to both inform and serve as the foundation for fruitful dialogue. For example, Table 5 illustrates results shared with participants in relation to general levels of trust in their own and other communities. At report-back meet- 
ings, this information served as a general platform for discussing the issues that contributed to or eroded trust. The themes explored by the questionnaire were:

- Trust and overall satisfaction (including service and accountability)

- Billing and pricing

- Infrastructure

- Environment

- Conflict

- Health and hygiene

Report-back and focus groups: Results from the surveys were tabulated and all participants invited personally to attend a presentation of findings held in their respective communities. Efforts were made to find a day and time that suited the greatest number of participants. Representatives of EWS' upper management structure were present to answer questions and concerns and to make the case for further two-way dialogue between interested parties and EWS. Approximately $25 \%$ of people attended the report-back meetings and in each case, the majority of people in attendance expressed their willingness to sit on a focus group that meets quarterly with EWS to help inform service improvement programmes. At the time of publication, the $2^{\text {nd }}$ quarterly focus group meeting had taken place in all 3 areas with approximately $80 \%$ retention rate, with some substitution.

\begin{tabular}{|l|c|c|c|}
\hline \multicolumn{4}{|c|}{ TABLE 5 } \\
Levels of general trust \\
\hline I trust EWS & Agree & Disagree & I don't know \\
\hline uMlazi & $51 \%$ & $44 \%$ & $5 \%$ \\
\hline KwaMashu & $64 \%$ & $33 \%$ & $2 \%$ \\
\hline Newlands East & $76 \%$ & $11 \%$ & $13 \%$ \\
\hline
\end{tabular}

In summary then, the research undertook a synthetic approach to building trust. This included a community engagement strategy combining transparency, visibility and local capacity-building, a customer service satisfaction survey with people who live and work in caring professions in the area, and the opportunity for participants to join a practical solution-oriented focus group, meeting with EWS four times a year. Community participation in questionnaire design with a full circle community reporting back served to generate the trust and social capital required for sustained dialogue.

\section{Issues of concern emerging from pilot surveys}

In each area, between 45 and 65 interviews were conducted. Responses were useful towards surfacing the broad pattern community concerns. Issues identified have served as the basis for focus group brainstorming sessions:

- Questionnaires were used to identify broad issues

- Groups were tasked with drilling down into the root causes of these problems and thinking creatively about what ideal solutions would look like, if designed from the bottom up.

As an early example, all communities identified problems with the clarity and utility of bills for understanding use patterns, leak alert, etc. Consequently, a recent focus group meeting was used to help evaluate a proposed format for the water and sanitation component for the new consolidated municipal bill. This resulted in several modifications to achieve greater clarity (Joseph, 2007). In the future, it is expected that focus groups will play an integrated role in the development of new policy, from cradle to implementation.
Key issues of concern for future focus group meetings include:

\section{All cases}

- Consider greater clarity for water and sanitation components on municipal bills

- Renew and strengthen information dissemination strategies related to Water Loss Insurance and Debt Relief

- Debt and affordability issues require review; consider tariff structure adjustment

- School disconnections require institutional intervention, especially in KwaMashu

- Develop a management strategy to address perceptions of relative satisfaction (i.e. relative to services in other areas)

- Develop strategic conflict reduction plan to bridge boundaries between differing water and sanitation technology and pricing regimes (especially around shared water points and shared water meters in Newlands East)

- Leverage high levels of concern for the environment by aligning initiatives to sustainability goals and principles.

\section{More acute in Newlands East and KwaMashu}

- Visible health and hygiene education campaign required

- Investigate episodic staff discipline problems and/or poor service record

- Replace any residual shared meters - especially in schools

- Clarify roles and responsibilities in tenant/landlord relations

- Define and diffuse tensions in Siyanda (informal settlement) around illegal connections and sub-contracted construction.

For further discussion of substantive issues emerging see Wilson and Pfaff (2008).

\section{Evaluation of methodology}

At the time of publication, 6 areas and one special study with people with physical disabilities were complete using this approach. In all areas, report-back meetings have yielded the successful creation of the focus groups. In 5 areas, the first official post-pilot phase focus-group meetings have taken place. In line with the vision, groups are contributing to bringing local concerns into focus and are providing critical information for the effective implementation of concrete service improvements. For example, focus groups have served to identify where local service centres keep irregular hours, have helped to inform common complaints with contextualised local knowledge, thereby allowing staff to better understand root causes of the most frequent triggers of low service satisfaction levels. Discussions have also shed considerable light on local attitudes towards and impact of illegal connections and ways to identify households in crisis where stigma prevents people from coming forward for assistance, among other issues. Call-centre staff also report that people calling in from areas where the study has taken place are better informed and better able to direct their complaints towards effective resolution (MacLeod, 2007).

A more comprehensive discussion of the substantive study results is beyond the scope here. Rather, in terms of trust and social capital, initial results indicate that the research process is promising for generating creative and sustained dialogue between EWS and consumers, while at the same time, structuring dialogue in ways that usefully informs policy and practice. 


\section{Acknowledgements}

The authors appreciate research assistance from the following University of KwaZulu-Natal (UKZN) students: Eleanor Hazell, Wiseman Luthuli, Scebi Mkhize, and Jason Musyoka; local research assistants: Nikita Fynn, Deborah Khuzwayo, Thanda Mbokazi, Philani Mncube, and Bafana Zungu; and Lulu Dlamini and Sibusisiwe Thusi from EWS. For reportback support, we thank Michael Singh, Stalyn Joseph, Bernard Gabela and Thabani Gcabashe from EWS and the Street Theatre players. We are grateful to two anonymous journal reviewers, as well as Prof Chris Buckley (UKZN), Prof Patrick Bond (UKZN), and Neil MacLeod (EWS) for their valuable suggestions. The UK Department for International Development and the Memorandum of Agreement between eThekwini Water and Sanitation and the University of KwaZulu-Natal provided generous support.

\section{References}

ALCOFF L (1991) The problem of speaking for others. Cultural Critique. Winter. 5-32.

ASHTON PJ and HAASBROEK B (2001) Water Demand Management and Social Adaptive Capacity: A South African Case Study. Division of Water, Environment and Forestry Technology, CSIR, South Africa. 22 pp.

BALLARD R, HABIB A and VALODIA I (2006) Voices of Protest: Social Movements in Post-Apartheid South Africa. University of KwaZulu-Natal Press, Scottsville, South Africa. 437 pp.

BREIGER R (2004) The analysis of social networks. In: Hardy M and Bryman A (eds.) Handbook of Data Analysis. Sage Publications, London. 505-526.

BOND P (2006) Reconciliation and economic reaction: Flaws in South Africa's elite transition. J. Int. Affairs, Fall/Winter 60 (1) 141-156.

BOOYSEN S (2007) With the ballot and the brick: the politics of attaining service delivery. Prog. Dev. Stud. 7 (1) 21-32.

CLEAVER F and ELSON D (1995) Women and Water Resources: Continued Marginalization and New Policies. Gatekeeper Series No. 49 International Institute for Environment and Development, London. $15 \mathrm{pp}$.

DEPARTMENT OF WATER AFFAIRS AND FORESTRY (DWAF) (2005) Our Blueprint for Survival. DWAF, Pretoria, South Africa. 17 .

DEPARTMENT OF WATER AFFAIRS AND FORESTRY (DWAF) (undated) Guide to the National Water Act. DWAF, Pretoria, South Africa. $42 \mathrm{pp}$.

DEPARTMENT OF WATER AFFAIRS AND FORESTRY (DWAF) (2001) Generic Public Participation Guidelines. DWAF, Pretoria, South Africa. 66p.

DESAI A (2002) We are the Poors: Community Struggles in Post-Apartheid South Africa. Monthly Review Press, New York. 156 pp.

HAGG G and EMMET T (2003) Muddying the elephants' water: Policy and practice in community water supply. Politeia 22 (1) 67-92.

HARRISON J, PFAFF B, GOUNDEN T and BUCKLEY C (2004) Free Sustainable Basic Water and Sanitation: The Durban Experience.
Water and Wastewater Management in Developing Countries, Victoria Falls, Zimbabwe. 28-30 July. 7 pp.

HEMSON D (2002) Women are Weak When They are Amongst Men The Participation of Women in Rural Water Committees in South Africa. Integrated Rural and Regional Development Research Programme, Occasional Paper No. 3. HSRC, Cape Town, South Africa. $24 \mathrm{pp}$.

HOLDEN P and GROSSMAN D (2005) 'Working for Water' in a Democratic South Africa. In: Bass S, Reid H, Satterthwaite D and Steele P (eds.) Reducing Poverty and Sustaining the Environment: The Politics of Local Engagement. Earthscan, London, Sterling VA. 180-193.

JOSEPH S (2007) Personal communication. eThekwini Water and Sanitation. 10 Dec.

JUNKER B, BUCHECKER M, MU U and BOKER M (2007) Objectives of public participation: Which actors should be involved in the decision making for river restorations? Water Resour. Res. 43 (No. 10) W10438 DOI: 0.1029/2006WR005584

MACLEOD N (2007) Personal communication. eThekwini Water and Sanitation. 26 June.

McLENNAN A (2007) Unmasking delivery: Revealing the politics. Prog. Dev. Studies 7 (1) 5-20.

MOODY J and WHITE D (2003) Structural cohesion and embeddedness: A Hierarchical concept of social groups. Am. Soc. Rev. 68 (1) 103-127.

MOSTERT E (2003) The challenge of public participation. Water Policy 5 179-197.

MULLER M (2007) Parish pump politics: the politics of water supply in South Africa. Prog. Dev. Stud. 7 (1) 33-45.

NICOLI N and MTISI S (2003) The Politics of Water: A Southern African Experience. Sustainable Livelihoods in Southern Africa Research Paper 20, Institute of Development Studies, United Kingdom. 30 pp.

PAHL-WOSTL C (2002) Towards sustainability in the water sector: The importance of human actors and processes of social learning. Aquat. Sci. 64 394-411.

PERRET S, FAROLFI S and HASSAN R (eds.) (2006) Water Governance for Sustainable Development. Approaches and Lessons from Developing and Transitional Countries. CIRAD, EarthScan, London, UK. 295 pp.

SIGODI, MARAH, MARTIN (Pty) Ltd. (2007) The State of Community Consultation in the Provision of Water Services. WRC Report No K5/1616. Water Research Commission, Pretoria, South Africa. $61 \mathrm{pp}$

WILSON Z (2006) The United Nations and Democracy in Africa: Labyrinths of Legitimacy. Routledge, New York \& London. 252 pp.

WILSON Z and HAZELL E (2006) Report on the Up-To-Date Evidence that Challenges eThekwini's Designation as Continental Innovator. DFID Engineering KaR Programme: W1-17, 2002-2007, Second Order Water Scarcity in Southern Africa. Newcastle University and the Department for International Development, UK. 12 pp.

WILSON Z (2007) Final Hydropolitical Map Report for South Africa. DFID Engineering KaR Programme: W1-17, 2002-2007, Second Order Water Scarcity in Southern Africa. Newcastle University and the Department for International Development, UK. 23 pp.

WILSON Z and PFAFF B (2008) Religious, philosophical and environmentalist perspectives on potable wastewater reuse in Durban. Desalination 228 1-9. 